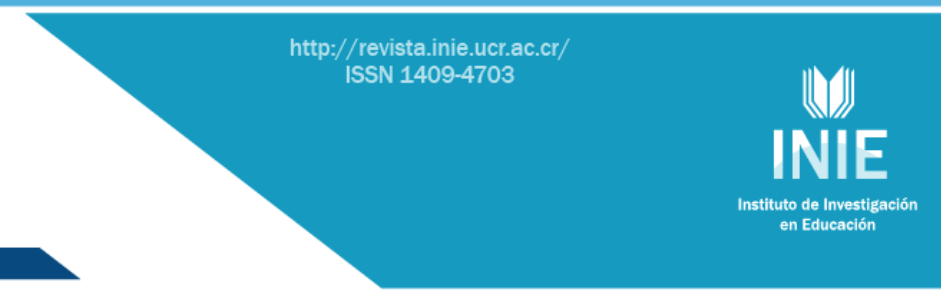

\title{
TRAYECTORIA DE LA INVESTIGACIÓN EN LA SEDE DE GUANACASTE, UNIVERSIDAD DE COSTA RICA \\ A CHRONOLOGY OF THE DEVELOPMENT OF ACADEMIC RESEARCH AT THE UNIVERSITY OF COSTA RICA, GUANACASTE BRANCH
}

\author{
Volumen 14, Número 2 \\ Mayo - Agosto \\ pp. 1-33
}

Este número se publicó el 30 de mayo de 2014

Cristina Castillo Briceño

Revista indizada en REDALYC, SCIELO

Revista distribuida en las bases de datos:

CATÁLOGO DE LATINDEX, IRESIE, CLASE, DIALNET, DOAJ, E-REVIST@S, SHERPA/ROMEO, QUALIS, MIAR

Revista registrada en los directorios:

ULRICH'S, REDIE, RINACE, OEI, MAESTROTECA, PREAL, CLASCO 


\title{
TRAYECTORIA DE LA INVESTIGACIÓN EN LA SEDE DE GUANACASTE, UNIVERSIDAD DE COSTA RICA \\ A CHRONOLOGY OF THE DEVELOPMENT OF ACADEMIC RESEARCH AT THE UNIVERSITY OF COSTA RICA, GUANACASTE BRANCH
}

\section{Cristina Castillo Briceño ${ }^{1}$}

\begin{abstract}
Resumen: El presente artículo hace referencia a la trayectoria del quehacer investigativo en la Sede Guanacaste y su aporte al desarrollo de la Región Chorotega, en el marco del cuarenta aniversario de su fundación. El texto presenta una sistematización general de las actividades de investigación realizadas desde sus inicios a la época actual, registradas en documentos oficiales existentes en los archivos de la institución, además de publicaciones en revistas científicas que para tal fin posee la Universidad de Costa Rica. Asimismo, ofrece testimonio de los aportes de la comunidad académica que ha dejado huella a lo largo de este recorrido cronológico de la Sede, primera institución de educación superior en la provincia de Guanacaste.
\end{abstract}

Palabras clave: HISTORIA DE LA INVESTIGACIÓN, EDUCACIÓN SUPERIOR, REGIONALIZACIÓN, COSTA RICA

Abstract: The purpose of this paper is to point out the research work pathway followed by Guanacaste branch of UCR and its contribution to the development of Chorotega region on its $40^{\text {th }}$ foundation anniversary. The paper explains the general systematization of the research activities carried out since the beginning of the current age. These activities have been registered in official documents in existing institutional files. Besides, the paper refers to scientific journals that have opened access to relevant publications. Moreover, the article provides evidence of a number of contributions performed by the academic community that has marked the path along the chronological journey of this campus, the first higher educational institutional in the province of Guanacaste.

Key words: HISTORY OF RESEARCH, HIGHER EDUCATION, REGIONALIZATION, COSTA RICA

\footnotetext{
${ }^{1}$ Profesora Asociada de la Universidad de Costa Rica, docente e investigadora.
}

Dirección electrónica: cristina.castillo@ucr.ac.cr

Artículo recibido: 23 de octubre, 2013

Devuelto para corrección: 5 de febrero, 2014

Aprobado: 15 de mayo, 2014 


\section{Introducción}

El nuevo contexto de la globalización del saber y de la educación demanda la necesidad de transferir el conocimiento generado a todos los niveles de la sociedad, como parte de una estrategia de desarrollo social y económico integral. Es así como la investigación científica y el desarrollo tecnológico constituyen un mecanismo estratégico para aumentar la capacidad de competir en la economía mundial y lograr el bienestar social. Por lo tanto, el presente artículo tiene como objetivo reconocer la trayectoria del programa de investigación en la Sede de Guanacaste, pues las universidades representan medios adecuados para fortalecer las capacidades nacionales de producción científica en un país.

El artículo inicia con una breve descripción del procedimiento seguido para recopilar la información, a fin de reconstruir la trayectoria de la investigación en la Sede Guanacaste. Temáticamente, se presentan los antecedentes que dieron origen a la creación del Centro Regional Universitario de Guanacaste, en adelante Sede Guanacaste de la Universidad de Costa Rica.

A continuación, se brinda una caracterización del quehacer de la investigación, según la normativa que le compete. Después, se realiza una caracterización de los diversos proyectos de investigación, se identifican temáticas por áreas, décadas y su vinculación con la oferta académica que ofrece esta unidad académica. Coyunturalmente, se esbozan las líneas generales y se dan a conocer productos académicos que han sido publicados en las revistas, que para tal efecto posee la Universidad de Costa Rica. Para dar paso, para terminar, a las conclusiones, como un espacio de reflexión que permita afirmar el compromiso institucional para con la investigación.

\section{Procedimiento}

Este artículo nace de la experiencia docente y como excoordinadora del Departamento de Investigación, al reflexionar sobre el desarrollo de la investigación en la Sede, más allá de las competencias técnicas que le corresponden por mandato del Estatuto Orgánico. La investigación bibliográfica se realizó tomando como base la documentación existente en los archivos de la Sede Guanacaste, relacionada con el área de investigación, fundamentalmente, los informes anuales de labores elaborados por los profesionales que han tenido a cargo la Coordinación de Investigación en este recinto universitario, actas y registros sobre el inicio, presencia y devenir de la investigación y artículos publicados por la comunidad 
académica de esta Sede. Para recopilar los datos, se confeccionó una plantilla de recolección de información denominada "ficha técnica", como un cuadro de doble entrada, en la cual se enlistó y registró cada modalidad de investigación desarrollada.

Se trató de recuperar la mayor cantidad de información posible, para acercarse al cumplimiento del objetivo propuesto y, así, esbozar un breve panorama de la situación de la investigación realizada. Parte de la información proviene de fuentes documentales, pues en la mayoría de los casos no fue posible obtener información de primera mano, por parte de los responsables de proyectos. Hecha esta salvedad, a continuación se presentan los resultados obtenidos.

\section{Breve recorrido en torno a los antecedentes y creación de la Sede de Guanacaste}

Hace cuarenta años, en marzo de 1972, inició labores el Centro Universitario Regional de Liberia, posteriormente denominado Centro Universitario Regional de Guanacaste y, en la actualidad, Sede Guanacaste de la Universidad de Costa Rica (UCR). Se creó como resultado de las necesidades sociales sentidas en esta provincia y ante la demanda nacional de descentralizar las instituciones estatales. Los antecedentes de la creación del Centro Regional Universitario de Guanacaste (CRUG), en la actualidad Sede Guanacaste, responden a diversos condicionantes que vivía el país, tales como:

pleno proceso de diversificación de la producción agropecuaria y de apertura hacia una industrialización con miras a reinsertarse desde otras perspectivas en el mercado mundial. La ganadería, el azúcar, el banano y el arroz fueron productos que despuntaron en esa diversificación, mientras que la producción de llantas y neumáticos, productos farmacéuticos de lujo, pinturas e insumos como el cemento y productos metal -mecánicos, junto con la fabricación de algunos bienes de consumo básicocaracterizaron la actividad industrial (). Con todo y las consabidas pugnas por impulsar distintos proyectos de desarrollo para el país (Rovira Mas, 1982), lo cierto es que ese rumbo de la producción nacional requería de profesionales que no había en abundancia en aquella época. Aparentemente, más costarricenses podían estudiar en el extranjero (), pero la demanda de profesionales calificados requería de una oferta más amplia que solo se podía lograr extendiendo las oportunidades de estudio en el país. (Castro, 2009, p.175) 
A su vez, a lo interno de la UCR se gestan condiciones propicias que refleja cierto clima favorable en la Universidad para proyectar el quehacer universitario fuera del campus de la Sede Rodrigo Facio, como fue "el movimiento gestado en el II Congreso Universitario realizado a finales de agosto y principios de setiembre de 1966" (Castro, 2009, p.175), tal como se puede evidenciar en la figura 1:

Figura 1: Condicionantes que favorecen la regionalización de la UCR

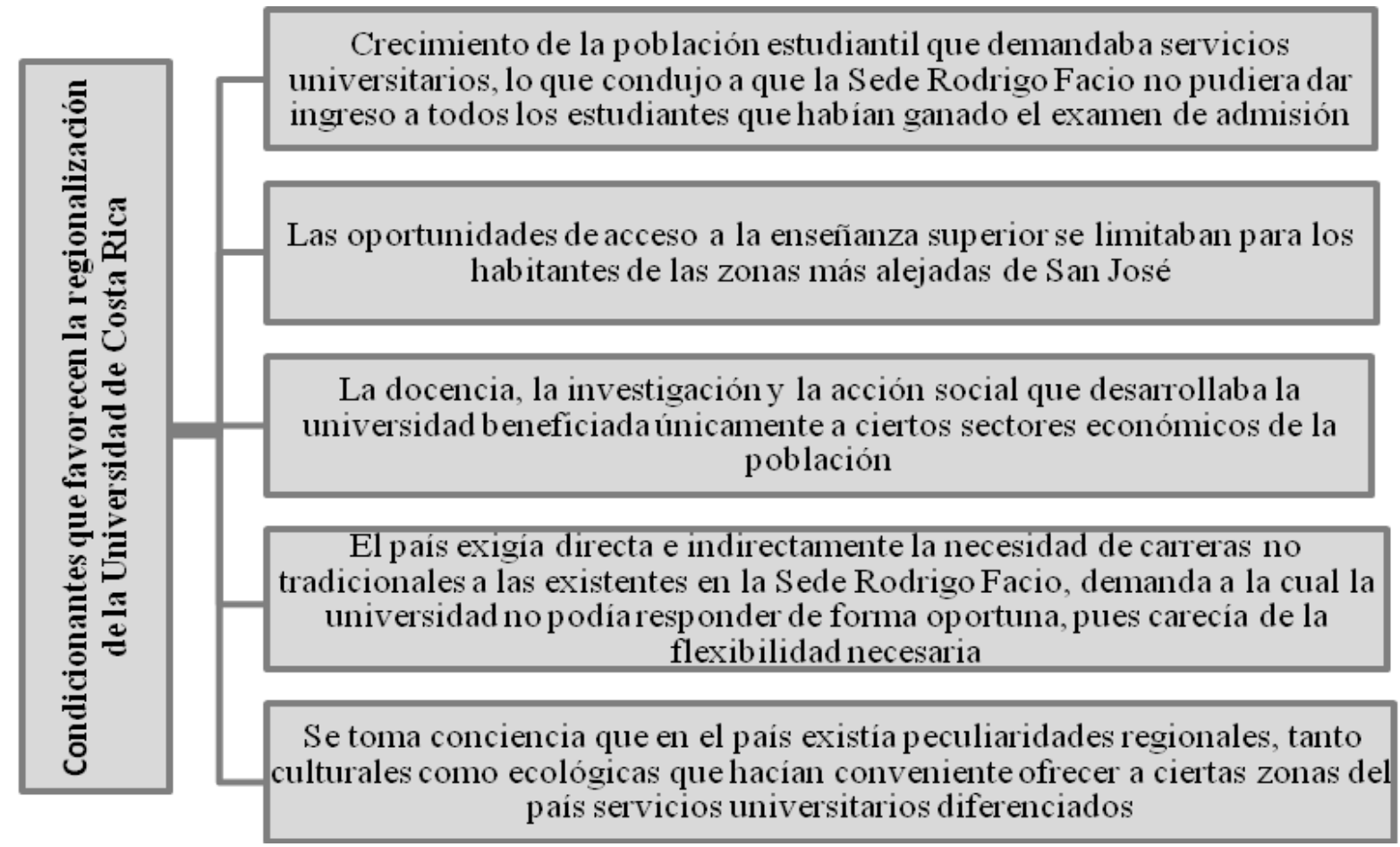

Fuente: Elaborado a partir de Alfaro y otras (1981, p. 38).

Con base al análisis de estas situaciones de exclusión universitaria a lo interno de la Universidad, se promovió la idea de extender su presencia en las demás comunidades del país, con lo que se logró la democratización de la educación superior, haciéndola asequible y brindándose en igualdad de posibilidades para todos los jóvenes de las zonas rurales, tal y como se expresa seguidamente: "Los Centros Regionales nacieron para cumplir con el precepto constitucional de igualdad de oportunidades educativas para todos los costarricenses, en los momentos que por decirlo así la Universidad de Costa Rica tenía el monopolio de la educación superior" (Durán, 1979, p. 9). 
Simultáneamente, algunas instituciones estatales de diferentes sectores sociales, estaban analizando la necesidad de descentralizar sus funciones y de acercarse a las comunidades más alejadas de la capital, para contribuir a satisfacer las necesidades de desarrollo social, cultural y económico de las diversas regiones del país.

Como resultado de ese análisis y reflexión sobre el quehacer universitario y de las condiciones de desarrollo que vivía el país, en 1972, abre sus puertas la Sede Guanacaste, como una unidad académica de la UCR, en el Barrio El Capulín de la Ciudad de Liberia, en las instalaciones de la Escuela John F. Kennedy, con una matrícula de 176 estudiantes, 9 profesores de las asignaturas de Humanidades, repertorios y requisitos de ingreso a carrera: Historia de la Cultura, Castellano, Filosofía, Apreciación Musical, Matemáticas, Sociología, Actividad Deportiva, Biología y Economía (Rosales, 1996). Es importante destacar que "anterior a esa fecha ya la UCR venía realizando la preparación de técnicos en la región a través de los cursos de verano que impartía la Facultad de Educación al personal del campo educativo" (Espinoza y Rosales, 2001, p.125). Posteriormente, se amplía la oferta de cursos de carreras como Educación y Diplomado en Administración de Empresas.

En este sentido, es menester mencionar que la Sede Guanacaste realizó las funciones al amparo de lo dispuesto en el Estatuto Orgánico de la UCR, ya que es hasta 1990 que se crea el capítulo IX en el Estatuto Orgánico, dedicado exclusivamente a las Sedes Regionales; se establece la tarea de estas en el desarrollo de la política de regionalización educativa, sus órganos decisorios y competencias de éstos. En específico, los numerales 108 bis y 109 son

los que se refieren a la formación de profesionales y técnicos. Se estipula en el artículo 109, inciso d, que dichas unidades académicas deben orientarse a "Proponer, ejecutar y servir de apoyo a programas de investigación y acción social que contribuyan al desarrollo de la región, en particular y del país en general” (UCR, 1990, p. 67).

\section{Desarrollo de la investigación en la Sede de Guanacaste}

La trayectoria de la investigación en la Sede Guanacaste ha sido el resultado de un amplio conjunto de factores contextuales, que han incidido en ella, como se mostrará en los apartados siguientes. 


\subsection{La investigación en sus primeros años}

De esta manera, a partir de los aspectos antes mencionados, el desarrollo y crecimiento del Centro Regional de Guanacaste, así llamado en los primeros años, avanzó muy lentamente en el área de investigación, "hasta 1979 no se han realizado investigaciones de forma sistemática. Se han elaborado monografías sobre los diez cantones de la provincia y un proyecto de coordinación con la Estación Experimental para la siembra de frijoles y frutas" (Alfaro y otras, 1981, p. 49). La situación se debió, especialmente, a la carencia de recursos que impedían asignar presupuesto a proyectos de investigación. Como se puede observar, la práctica de investigación en esta sede universitaria se empezó a desarrollar relativamente tarde. No obstante, es importante destacar que desde sus inicios estuvo presente en esta Sede el interés de realizar investigaciones que contribuyeran al desarrollo de la provincia de Guanacaste; sin embargo, el problema presupuestario siempre fue una limitante a estas aspiraciones. En este sentido, Caamaño (1972, p. 7) se refiere a los propósitos iniciales del Programa de Investigación, en los siguientes términos:

Se establecerá con el propósito de servir como factor de coordinación científica y tecnológica que se realice en el campo regional. La Universidad de Costa Rica de esta manera, podrá coordinar estas labores de Investigación con los organismos nacionales que se dediquen a estos menesteres... Fundamentalmente, podrá ser una investigación operativa de acuerdo con las necesidades de la zona. Una comisión especialmente nombrada haría los estudios para la creación del programa.

De acuerdo con lo transcrito, en los documentos oficiales surgidos al calor de los ideales esperados con la apertura de los Centros, se expresan grandes e importantes ideas para satisfacer las necesidades del desarrollo social, cultural y económico de la región; sin embargo, las quejas por la falta de incentivos a esta área han sido una constante y han menoscabado el logro de estos planteamientos. El Centro Regional de Guanacaste no fue la excepción. No obstante, Hernández (1974, p. 127) señala:

Impulsé la investigación sobre Guanacaste, entre mis compañeros de este Centro Regional como homenaje a la provincia, en el sesquicentenario de la Anexión del Partido de Nicoya a Costa Rica, y porque creo que esta institución debe contribuir actuando para un desarrollo integral de la región, que además deja en el conocimiento científico, debe fundamentarse en su propio sistema de educación. 
Es así como, bajo la iniciativa de la licenciada Mireya Hernández Faerron, directora del Centro Regional y del grupo de profesores de Estudios Generales, se tomó en conjunto la decisión de que la actividad académica denominada "ensayos", que debían desarrollar los estudiantes a través de diversas investigaciones, habrían de ser sobre temas de la región, con la colaboración de sus profesores para su publicación. De tal manera, se estructuran cuatro series de publicaciones, denominadas Cuadernos de Guanacaste, a saber:

- $\quad$ Lengua, Literatura y Folclore.

- Historia, Geografía y Etimología.

- Recursos Naturales y Mesología.

- Documentos.

Asimismo, tanto estudiantes como académicos, no solo se interesaron en conocer la realidad de su entorno, sino que contribuyeron a sistematizar valiosa información que, muy probablemente, se encontraba dispersa o en el anonimato. Como producto de esta experiencia, se publicaron dos cuadernos de la serie I: Lengua, literatura folclore, según lo expresa Hernández (2013) en su discurso del XL Aniversario, Sede de Guanacaste, con los títulos de:

- Guaitil, una reserva autóctona en peligro, donde se da a conocer que en la comunidad de Guaitil, ubicada en Santa Cruz, se hacen hermosas obras de barro con materias primas y técnicas tradicionales y ancestrales de los indígenas chorotegas, de Mireya Hernández Faerron y Flora Marín de Sasa.

- Las comidas y bebidas de Guanacaste, de Guillermo García Murillo y Luis Efrén García Briceño, recopiladores del arte culinario guanacasteco.

En concordancia con lo anterior, en ese mismo año se publica la Revista $N^{\circ} 38$ de la Universidad de Costa Rica, con el apoyo de la Vicerrectoría de Acción Social y con académicos, tanto de la Sede Central como del Centro Regional, quienes publicaron sus investigaciones a modo de ensayos y artículos sobre Guanacaste, con el propósito de incorporar a la UCR en las actividades de celebración del sesquicentenario de la Anexión que la provincia de Guanacaste conmemora durante 1974. Las temáticas de estas publicaciones reflejan aspectos específicos de la región, al abordar tópicos como: 
- Anexión del Partido de Nicoya a Costa Rica, de Rosa Greñas Morales.

- Las zonas de vida de Guanacaste, de Luis Founier O.

- El Guanacaste, de Constantino Láscaris.

- El coyol, vino guanacasteco, de Guillermo García Murillo y Sergio Chaves Chaves.

- Liberia: Un proyecto de investigación en Sociología Urbana, de Alonso Calvo Pardo.

- Nicoya y sus templos históricos, de Carlos Meléndez Chaverri.

- La municipalidad de Nicoya, de Ligia Cavallini de Arauz.

- Población escolar de Guanacaste y cambio en la administración del sistema, de Abelino Villegas Bustos.

- La vida en las minas de Abangares y la novela histórica de José León Sánchez, La Colina del buey, de Guillermo García Murillo.

- Muestra de autores guanacastecos, de Juan Antonio Velit Grant.

- Reseña crítica de algunos libros y estudios sobre Guanacaste, de Mireya Hernández Faerron.

- Nicoya, una geografía cultural. Traducción, de Anne Langerak Pater.

A modo de ilustración, se reseñan tres de ellos en la Figura 2, por trazar rasgos relevantes en sobre Guanacaste. El primero trata temas en torno al ser de Guanacaste, desde su actividad productiva y riqueza natural, hasta el clima y lo cultural; el segundo trata una de las tradiciones particulares de esta zona, cual es la extracción y preparación del vino de coyol, para ser utilizado en la celebración de fiestas, una herencia de los indígenas chorotegas que se ha extendido al pasar de los años y que se mantiene viva entre los guanacastecos; el último, se refiere a la Municipalidad de Nicoya, como importante órgano de administración de la justicia y gestión del proceso anexionista a Costa Rica que experimentó esa zona del país. 
Figura 2. Artículos y ensayos publicados en la Revista 38 de la UCR

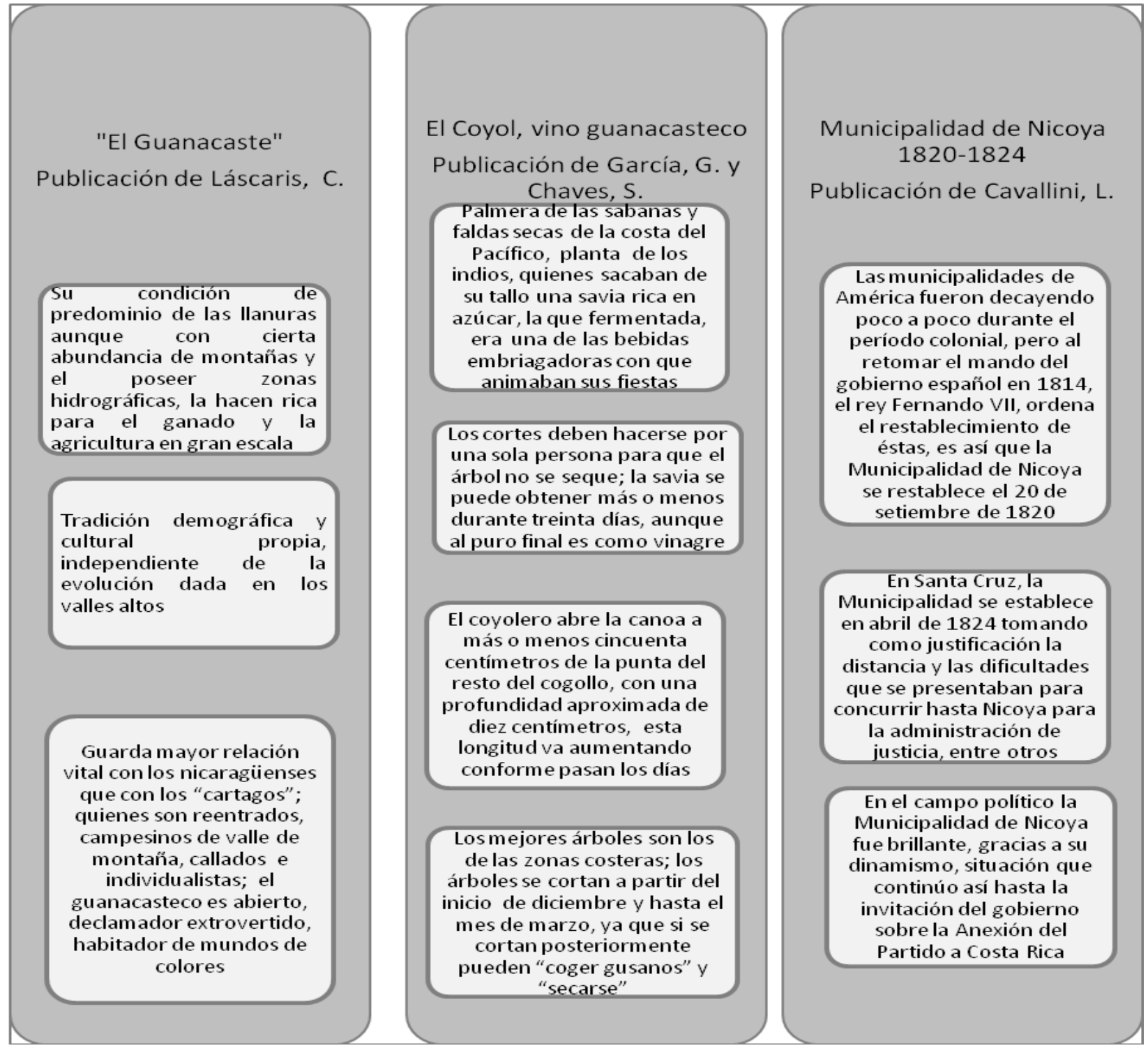

Fuente: Elaboración propia a partir Láscaris (1974), García y Chaves (1974) y Cavallini (1974). 
Como se puede apreciar en la publicación de Láscaris (1974), se destacan las condiciones naturales que posibilitan la producción agrícola de arroz, caña y otros cultivos que permiten su progresiva mecanización; así mismo, el desarrollo de la actividad ganadera de la región en gran escala; en cuanto al ser guanacasteco destaca su expresión cultural llena de color, humor, espontaneidad. Estas particularidades le han dado a Guanacaste una conformación socioeconómica de condiciones que la distinguen del resto del país.

Mientras, García y Chaves (1974) rescatan, a través de la tradición oral, un aspecto poco conocido en torno al folclórico y legendario árbol de coyol, su historia y procedimiento ancestral para obtener la savia del tronco que, al fermentarse, se convierte en una bebida parte de la cultura netamente guanacasteca, llamada el vino de coyol.

En cuanto a la publicación de la Municipalidad de Nicoya 1820-1824, Cavallini (1974) esboza los principales hechos políticos sobre la Municipalidad después de restablecido el Ayuntamiento en 1820, la fundación del Ayuntamiento de Santa Cruz en 1824, así como el movimiento de Anexión del Partido de Nicoya a Costa Rica. Estos acontecimientos reflejan el pensamiento de la ciudadanía de la época en torno al acontecer social, político y económico.

Coyunturalmente, en el año 1977, se celebra el Centenario del Cantón de Carrillo, ocasión en la que se documenta y publica la Monografía del Cantón de Carrillo: 1877-1977, de Mireya Hernández Faerron, Carlos Dávila Cubero y Julio César Jaén, como una actividad más del quehacer investigativo del Centro Regional de Guanacaste. En ese mismo año, se publica el libro Mario Cañas Ruiz, Un artista guanacasteco, escrito por profesor universitario de Filosofía Guillermo García Murrillo (1977), personaje reconocido de la vida liberiana, quien contribuyó a narrar su entorno en los tiempos de los sabaneros y montadores de toros legendarios, como Charío Fuentes, Jesús Gallo y Camilo Reyes.

En este contexto, se evidencian deslindes de voluntad política institucional de hacer realidad la acción investigativa en este Centro Universitario, en cumplimiento con el mandato establecido en el Estatuto Orgánico de la Universidad de Costa Rica, dado que tiene la misión de incidir en su entorno para dilucidar sus orígenes, mostrar los perfiles significativos de sus gentes, de su tierra, exponer sus problemáticas y rescatar sus valores. Por lo tanto, la Universidad, como institución de la ciencia y la cultura, favorecerá que la sociedad y los individuos participen en la cultura y ayudará a crear una visión científica, que permita esclarecer sus raíces y problemas para asumirlos y actuar. 
Por consiguiente, se certifica que a una institución de Educación Superior le compete, con toda su estructura organizativa, recursos humanos y técnicos, cumplir con el encargo social de dar respuesta ante la constante incertidumbre que han enfrentado los pueblos acerca de sus orígenes, contribuir a delinear los desafíos en armonía con su entorno social, ambiental e intercultural.

Posteriormente, se continúan realizando esfuerzos para proponer ante las respectivas instancias universitarias algunos proyectos de investigación, con miras a lograr presupuesto para esta área; es así como en el Plan Quinquenal de 1978 se tramitaron algunos proyectos orientados al Patrimonio Cultural de la región y a sus recursos naturales, se crea una instancia de investigación a manera de Unidad de Investigación, con el propósito de facilitar el desarrollo de esta área del quehacer universitario (Murillo, 1979). A modo de ejemplo, se ilustra en la Figura 3 los temas de proyectos de investigación del Plan Quinquenal, los cuales muestran el esfuerzo de vinculación con la realidad.

Figura 3. Temática del Plan Quinquenal

\begin{tabular}{l} 
A. Patrimonio histórico \\
cultural \\
\hline -Museo Universitario \\
Regional \\
- Monografías de Guanacaste \\
- Tradiciones y folclore \\
guanacasteco \\
-Antropología : sociedad y \\
cultura de Guanacaste \\
-Problemática agraria de \\
Guanacaste y sus \\
implicaciones socio- \\
económicas
\end{tabular}

B. Recursos Naturales del
Pacífico Norte

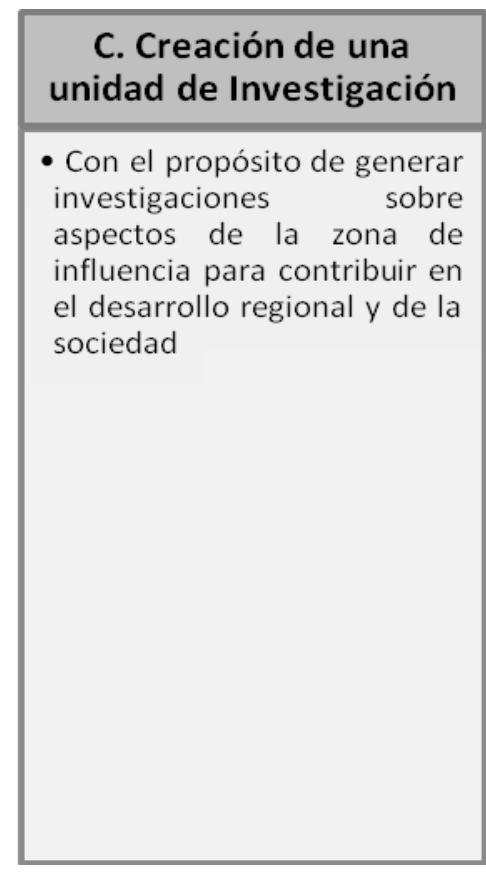

Fuente: Elaboración propia a partir de Murillo (1979).

Según se puede apreciar, las iniciativas de investigación surgieron mucho tiempo después de la apertura de la Sede, seis años después, aproximadamente, no así los recursos 
necesarios para desarrollarlos, que a la postre constituyó una limitante y factor de falta de estímulo a las actividades de investigación. Al referirse a estos anteproyectos, Murillo (1979, p. 40) señala que se podrían denominar "los buenos deseos del Centro", debido a que si bien es cierto su temática era importante por su vinculación con la zona, algunos de ellos no cumplieron con los requisitos, por lo cual tuvieron que excluirse.

Evidenciando aún más las diversas dificultades que tuvo el desarrollo de la investigación en los primeros años de labores del Centro, este mismo autor afirma que los proyectos elegidos

sufrieron interminables estudios de parte de varios entes universitarios y llegaron a la Vicerrectoría al finalizar el año 1978 (...) y no fue hasta el 1 de agosto de 1979 que se informó a la Coordinación del Centro que debían revisarlos y esperar a que otros fueran presentados (...) Poco tiempo después, se cambió el coordinador de Investigación en este Centro. (Murillo, 1979, p. 41)

De la cita anterior se notan las trabas administrativas y la carencia de una política clara de descentralización en materia de investigación, que permitieran un acompañamiento real por parte de la Sede Rodrigo Facio, y que dieron al traste con estas iniciativas para apoyar las prioridades de investigación. Lo anterior contribuyó a desestimular la investigación en el Centro, de tal forma que "el estado del Centro en este campo, es peor" (Murillo, 1979, p.41).

Como se puede apreciar, aunque los académicos del Centro proponían sus iniciativas de proyectos, los trámites burocráticos obstaculizaban la posibilidad de desarrollarlos; es decir, no pasaban del papel y de una intencionalidad manifiesta. Por su parte, en La Investigación en Guanacaste, de Murillo (1979, p. 30), revela que la falta de recursos humanos ha sido una de las debilidades enfrentadas por el Centro:

La situación en el Centro se ve agravada por contar en la actualidad con 85 profesores y solo 18 en el régimen académico (...) Esto se refleja en una falta de continuidad del personal, lo mismo a lo largo de los semestres, así como en la permanencia muy corta, entre 36 y 60 horas para la mayoría del profesorado (...) La mayoría de este cuerpo viajante no se interesa por investigar; los que cambian semestralmente, no lo hacen.

Con base en lo anterior, se desprende que, además de la carencia presupuestaria, de políticas universitarias integrales, de las trabas burocráticas, del poco personal docente 
estable (solamente el $21 \%$ estaba en propiedad) y de la actitud no favorable para promover investigaciones en el profesorado, la investigación enfrentó dificultades para su desarrollo en el emergente Centro Universitario.

La investigación es una vía mediante la cual la docencia se puede hacer operativa y funcional en los distintos contextos de la acción docente, ya sea en el aula de clases o fuera de ella. La investigación debe estar motivada, además, por las necesidades reales de los entornos donde están insertos el Centro, los educandos y las instituciones en las que estos convergen; por ello, docencia e investigación se relacionan ineludiblemente con la vinculación social. Dice el pedagogo italiano Francesco Tonucci (1999, p. 19), citado por Rivas (2011, párr. 6), que la universidad:

será siempre un momento (cultural) de análisis de la realidad y que la investigación será el modo, el método por el que se realiza dicho análisis. Por consiguiente, no puede prescindirse de la realidad: hay que partir de ella, pero no para rehacerla, no para copiarla, sino para analizarla y comprenderla con vistas a cambiarla.

En ese sentido, Murillo (1979, p. 40) reitera su preocupación por las situaciones que se presentan en torno al desarrollo de la investigación, en los siguientes términos:

No se puede pensar que el Centro Universitario de Guanacaste, sea universidad, en tanto que no exista investigación científica; así no pasará de ser una entidad docente, informática, de repetición de conocimientos y no un ente creador de conocimientos nuevos como exige la definición de Universidad.

Desde esta perspectiva, hay una queja constante, un sinsabor por parte de algunos miembros del personal docente del Centro, interesados en impulsar proyectos de investigación científica. De igual manera, el mismo autor denuncia que no hay libertad para resolver los problemas que enfrenta el centro, por la centralización en la toma de decisiones:

Los problemas de los Centros se consideran solamente en segundo plano (...) una vez resueltos los problemas de la Sede (...) Los Coordinadores de los Centros (...) tienen que limitarse a exponerlos ante la Vice-rectoría, esperar la resolución de esta, sin tener ninguna posibilidad real de influir y determinarse las decisiones que afectan la solución de sus problemas. (Murillo, 1979, p. 45) 
Es importante destacar que conforme se fue consolidando el Centro en infraestructura, presupuesto, estructura organizativa y recursos humanos, también fue creciendo el interés por desarrollar investigación en diversos campos, acorde con las necesidades de desarrollo de la región, las ofertas académicas y el interés y formación del profesorado. No obstante:

hay sectores en los que la investigación ha adquirido cierto grado de desarrollo, pero presentan muchas carencias aún, y hay también sectores y unidades académicas en los que la investigación no ha sido incorporada como un protagonista en la vida cotidiana (Gutiérrez, 2005, p. 1).

La Sede de Guanacaste no ha escapado a esta realidad, dado que el personal docente no ha podido trascender las diversas tareas docentes administrativas para incorporar parte de su tiempo laboral a actividades de investigación y producción científica.

Como ya se ha expuesto, las investigaciones realizadas en la Sede estuvieron más relacionadas con el desarrollo de la docencia, mediante acciones orientadas a realizar investigaciones de temas asignados a los estudiantes, por parte de los académicos, las cuales finalizaban con la redacción de ensayos, que pocos llegaron a publicarse, o se publicaron muchos años después.

El estudio realizado en cuanto a la labor de la investigación en los Centros Regionales, demuestra el comportamiento embrionario de esta labor universitaria en dichos recintos:

La condición proyectiva de las reflexiones en torno al quehacer de la investigación en los Centros Regionales durante esta etapa, queda de manifiesto en el hecho de que esta función no logra consolidarse explícitamente en la configuración orgánica de estas unidades (Margery, 1976, p. 13)

El texto transcrito revela que, en sus inicios, la investigación en la Sede estuvo marginada en favor de la docencia. Sin embargo, en el análisis realizado por este mismo autor, se menciona que hubo algunas iniciativas aisladas, según lo confirma en su estudio, pero no, como proyecto institucional:

También, es preciso reconocer que dicha actividad, de la que hay notables y valiosos testimonios, fue llevada a cabo en forma individual y que, en muchos casos, representó la continuidad de proyectos y trabajos que muchos profesores habían iniciado en 
escuelas y facultades de la capital y que lógicamente prosiguieron en los centros de provincia, luego de su traslado. (Margery, 1976, p. 13)

Es decir, dichas investigaciones no tienen relación alguna con las condiciones propias de la región en la cual está inmerso el Centro; es decir, no respondían a necesidades del entorno, fueron ideas concebidas en otra realidad académica, económica, social, cultural, ni a políticas corporativas del Centro como tal. Lo anterior demuestra que no fue posible desarrollar muchas labores, entre estas las funciones de investigación, durante muchos años, ante la citada realidad. Esto se reafirma en las conclusiones obtenidas del Trabajo Final del I Congreso de CURG, celebrado entre el 7 y 10 de agosto de 1979: "Exigir que, siempre dentro de la máxima independencia, se le brinden al CUGR, los recursos necesarios para que puedan desarrollarse en Docencia, Administración, Investigación, Acción Social y Vida Estudiantil" (Fonseca, 1979, p. 38).

De esta forma, la Sede de Guanacaste no fue la excepción, como puede notarse, la actividad investigativa desde sus inicios estuvo confinada a una serie de limitaciones presupuestarias, carga docente, infraestructura, líneas o tópicos de investigación, ausencia de un cuerpo docente consolidado, mecanismos de estímulo y centralización de la toma de decisiones en la Sede Rodrigo Facio, dado que toda vez que, por un lado, los anteproyectos pasaban los requisitos establecidos a nivel del Centro, debían elevarse ante las instancias respectivas de la Vicerrectoría de Investigación para iniciar otro proceso de revisión y aceptación, lo que generaba desmotivación y que la actividad fuese vista como privilegio de una élite académica. Por otro lado, la biblioteca universitaria necesitaba mayor dotación de recursos para apoyar la docencia, el aprendizaje y la investigación, y se convierta en el eje esencial para el desarrollo de los procesos de gestión de información y del conocimiento.

Por consiguiente, ante un contexto universitario que prioriza la actividad docente sin hacer inversión presupuestaria en la actividad investigativa y la tecnología, por parte de la comunidad docente se continúa con iniciativas de investigaciones individuales y sujetas a condiciones y posibilidades personales. Este escenario amenazó la capacidad de alcanzar importantes resultados a nivel de la investigación. 


\subsection{La Investigación en la Sede}

Luego de este periodo de desarrollo limitado y sin líneas de investigaciones definidas y articuladas a las políticas de la Sede con la región, en la década de los 80 va a tener un mayor avance la investigación, aunque siguen prevaleciendo cierto tipo de situaciones condicionantes. No obstante, con la consolidación de un cuerpo docente en propiedad, o de nombramientos continuos y de apoyo de recursos bibliotecarios, se va a facilitar un mayor impulso a la actividad investigativa.

En este escenario surgen los primeros productos de investigación en el campo agropecuario, social, desarrollo regional y cultural, entre otros. A modo de resumen, en el siguiente gráfico se muestra la trayectoria por áreas que ha seguido la investigación en la Sede, desde 1983 hasta 1994, donde se observa la preeminencia de temática agropecuaria sobre las demás.

Gráfico 1. Sede de Guanacaste. Proyectos de Investigación 1983-1994 por áreas

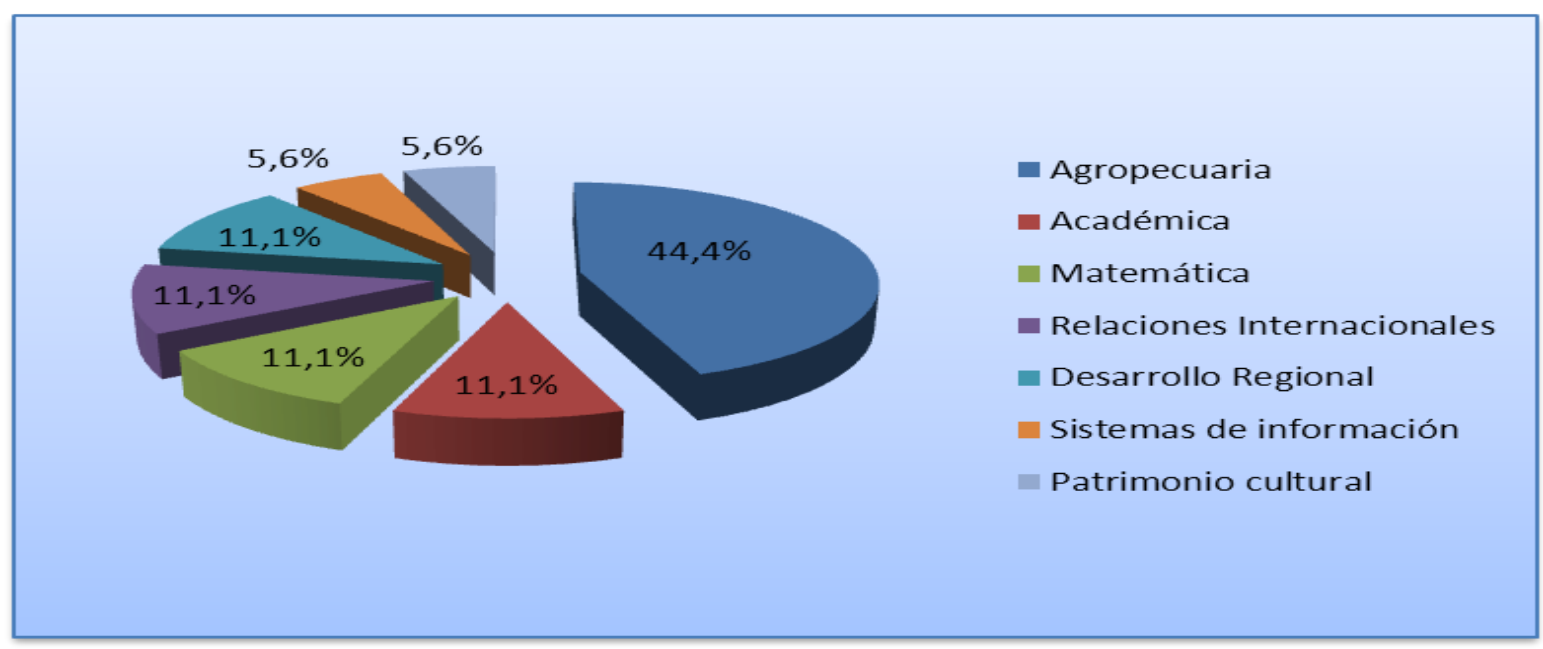

Fuente: Elaboración propia a partir de Loría (1997).

Como se puede observar, en el Gráfico 1 hay un predominio de más de un tercio de los proyectos de investigación en el área agropecuaria, dada la vocación productiva de la zona y la presencia de la carrera de Agronomía en la Sede de Guanacaste. Además, unido el porcentaje anterior al del Desarrollo Regional y Patrimonio Cultural se muestra un total del $61,1 \%$ de respuesta con la zona, dato significativo con respecto a los procesos de vinculación 
con el sector productivo, con el fin de abordar de manera más sistemática los problemas productivos regionales, los cuales se enumeran en la figura 4.

Figura 4. Sede de Guanacaste. Proyectos de 1983 a 1993 por áreas y aspectos investigados

\begin{tabular}{|c|c|c|}
\hline $\begin{array}{l}\text { Total de } \\
\text { proyectos }\end{array}$ & Áreas & Títulos de los proyectos de investigados \\
\hline 8 & Agronomía & $\begin{array}{l}\text { Evaluación de pastos de corte y pastoreo en Guanacaste } \\
\text { Contribución del modelo de cooperativas agrarias al desarrollo regional } \\
\text { durante 1975-1985 } \\
\text { Pastos de corte y piso en Guanacaste } \\
\text { Clasificación taxonómica de malezas } \\
\text { Manejo integrado de malezas en arroz } \\
\text { Generación y adaptación de tecnología para almácigos } \\
\text { Mejoramiento de leguminosas } \\
\text { Rescate de especies vegetales mesoamericanas }\end{array}$ \\
\hline 2 & Informática & $\begin{array}{l}\text { Estabilidad de sistemas interconectados compuestos por subsistemas } \\
\text { de distinto tipo } \\
\text { Creación de un centro de información y documentación sobre la Región } \\
\text { Chorotega }\end{array}$ \\
\hline 2 & $\begin{array}{l}\text { Patrimonio } \\
\text { Cultural }\end{array}$ & $\begin{array}{l}\text { Rescate de la canción popular guanacasteca } \\
\text { Alternativas de potenciar el desarrollo regional dando a conocer los } \\
\text { valores culturales del guanacasteco para rescate de la identidad }\end{array}$ \\
\hline 1 & $\begin{array}{l}\text { Trabajo } \\
\text { Social }\end{array}$ & Enseñanza -aprendizaje del Trabajo Social en la Sede de Guanacaste \\
\hline 1 & Turismo & $\begin{array}{l}\text { Proyecto de riego Arenal- Tempisque y su impacto socioeconómico en la } \\
\text { provincia de Guanacaste }\end{array}$ \\
\hline 1 & Matemática & Dar a conocer el uso de métodos clásicos del tipo Newton-Rapson \\
\hline
\end{tabular}

Fuente: Elaboración propia a partir de Universidad de Costa Rica (1993).

Posteriormente, Loría (1997) indica que en el año 1996 existían 13 proyectos de investigación, relacionados con temáticas como la narrativa, cultura, valores y ecología; sin embargo, la mayoría de estas iniciativas pertenecían al sector agropecuario, probablemente, tomando en cuenta la vocación de la provincia en este campo. Además, merece destacar el énfasis de las temáticas de investigación en 1996 de los proyectos impulsados, ya que de los 13 planteados en ese momento, 8 corresponden a aspectos vinculantes con el sector agropecuario y tres referentes a aspectos culturales, tal y como se muestra en la figura 5. 
Figura 5. Proyectos de investigación, Sede de Guanacaste, 1996

\begin{tabular}{|c|c|}
\hline Área & Título del proyecto \\
\hline Literatura & La concepción del mundo en la narrativa costarricense \\
\hline Literatura & Estudio etnolingüístico del cuento popular tradicional \\
\hline Agronomía & Evaluación de pastos de corte y pastoreo en Guanacaste \\
\hline Agronomía & $\begin{array}{l}\text { Clasificación de malezas y control de las mismas en los principales cultivos } \\
\text { de Guanacaste }\end{array}$ \\
\hline Agronomía & $\begin{array}{l}\text { Comportamiento fenomenológico del cultivo del pejibaye, sembrado bajo } \\
\text { riego en el trópico seco de Costa Rica }\end{array}$ \\
\hline Agronomía & $\begin{array}{l}\text { Adaptación ecológica de plantas medicinales criollas y exóticas en la Finca } \\
\text { Experimental de la UCR, Santa Cruz, Guanacaste }\end{array}$ \\
\hline Agronomía & $\begin{array}{l}\text { Recolección, reproducción y adaptación de frutales no tradicionales y } \\
\text { exóticos del Trópico seco en Costa Rica }\end{array}$ \\
\hline Agronomía & Mejoramiento de la producción de leguminosas industrializables \\
\hline Agronomía & $\begin{array}{l}\text { La contribución del modelo de cooperativas agrarias al desarrollo de la } \\
\text { Región Chorotega }\end{array}$ \\
\hline Agronomía & Rescate de especies vegetales mesoamericanas \\
\hline Matemática & Métodos numéricos aplicados a ecuaciones lineales y no lineales \\
\hline Desarrollo Regional & $\begin{array}{l}\text { Guanacaste hoy: nuevas alternativas de desarrollo, conservación, rescate } \\
\text { de valores y sistema ecológico }\end{array}$ \\
\hline Rescate Popular & Rescate de la canción popular guanacasteca de tradición oral \\
\hline
\end{tabular}

Fuente: Elaboración propia a partir de Loría (1997).

Esto demuestra el interés institucional por contribuir desde la producción y aplicación del conocimiento con el desarrollo del contexto económico, cultural y social de esta región, lo cual permitió articular la producción de conocimiento con la acción social realizada y posibilitó, a su vez, descubrir relaciones para producir cambios que beneficiaran el desarrollo de la docencia y la proyección comunitaria a la región.

Simultáneamente, en 1997, con motivo de la conmemoración de los 25 años de labores de la Sede Guanacaste, la Revista de Ciencias Sociales № 75 dedica una edición especial a esta unidad académica universitaria denominada Guanacaste: Tradición y Futuro. En esta oportunidad, la sección central de este número está constituida totalmente por contribuciones de investigadores de dicha unidad académica $\mathrm{y}$, fundamentalmente, se tratan temas vinculados al quehacer de la Sede y de la zona, lo que muestra el grado de madurez alcanzado por esa comunidad educativa (Camacho, 1997). A continuación, en la figura 6, se muestran las respectivas publicaciones. 
Figura 6. Artículos publicados Revista de Ciencias Sociales $\mathbf{N}^{\circ} 75$

\begin{tabular}{|c|c|}
\hline Título de los artículos & Autores \\
\hline La guanacastequidad & Floria V.Díaz RiveL \\
\hline Los ritmos tradicionales de Guanacaste & Raziel Acevedo A \\
\hline Dormite, niñito. Canción de cuna. Análisis literario y musical & $\begin{array}{l}\text { Liubou Sliesarieva. } \\
\text { Santiago Quirós }\end{array}$ \\
\hline El Duque Marlborough en la Tradición Guanacasteca & Javier Martínez Merino \\
\hline Bagaces: un reencuentro histórico social & Hortenzia Meza \\
\hline Características psicosociales del estudiante de éxito escolar en Guanacaste & Ma. Elena Loáiciga G \\
\hline Cambios sociales y rol del adolescente en la estructura familiar & Wagner Moreno M \\
\hline La rehabilitación integral de la persona con discapacidad & Cristina Castillo B \\
\hline Semblanza histórica de la Sede de Guanacaste & Ana Ligia Loría Q \\
\hline La acción social y su contribución al desarrollo de la región Chorotega & Rosa Rosales O \\
\hline $\begin{array}{l}\text { Perspectivas vocacionales de los alumnos de IV ciclo de los colegios de la } \\
\text { región Chorotega }\end{array}$ & Elías Mójica \\
\hline Veinticinco años de las Ciencias Básicas en la Sede de Guanacaste & Vera Diez Martín \\
\hline $\begin{array}{l}\text { Evolución histórica de la Carrera de Trabajo Social de la Sede Universitaria } \\
\text { de Guanacaste y su impacto en la región Chorotega }\end{array}$ & Olga Villalta/Rosa Rosales \\
\hline
\end{tabular}

Fuente: Elaboración propia a partir de la Revista de Ciencias Sociales № 75 (1997).

Un aspecto a destacar en esta época es la implementación del Reglamento de la Sede Guanacaste, publicado en la Gaceta Universitaria (26-98, 24-09-98), como una regulación ordenada de disposiciones y lineamientos para llevar a cabo el quehacer universitario, ya que se establece la estructura, organización y competencias que tendrá la Sede Guanacaste para cumplir con las responsabilidades académicas, por lo que se considera que esto constituye un paso más en la consolidación de la Sede como unidad académica de la Universidad de Costa Rica.

Como logro relevante de esta nueva estructura y reorganización se destaca, en su organigrama, el carácter de departamentalización, es decir, se establece un proceso en el cual la Sede es dividida estructuralmente, delegando tareas en departamentos de acuerdo con alguna base o característica compartida, para dar una mayor unidad a áreas comunes; además, se definen, de manera específica, la responsabilidad que se le asigna a la Coordinación de Investigación, a saber en su artículo 18: 
Es responsable de promover y consolidar la producción de investigación, contribuyendo de esta manera al proceso de análisis y desarrollo de la región. Coordinar y utilizar los mecanismos, medios o procedimientos que estimulen la investigación, en concordancia con las políticas que sobre la materia dicten los órganos superiores de la institución. Sus componentes son los programas y proyectos de investigación que se desarrollan en la Sede Regional y el sistema de bibliotecas, documentación e información de la Sede Regional. (Universidad de Costa Rica, 1998, p. 4)

Como se puede apreciar, lo que se pretende es impulsar, gestionar, coordinar, dar seguimiento, arraigar procesos de investigación y proyectos de investigación como quehacer universitario, así como la dotación de material bibliográfico y documental adecuado para tal actividad y la difusión de los resultados investigativos. A su vez, en dicho Reglamento se establece lo que le corresponderá, específicamente, al Coordinador General de Investigación como funciones (figura 7).

Figura 7. Responsabilidades de la Coordinación General de Investigación

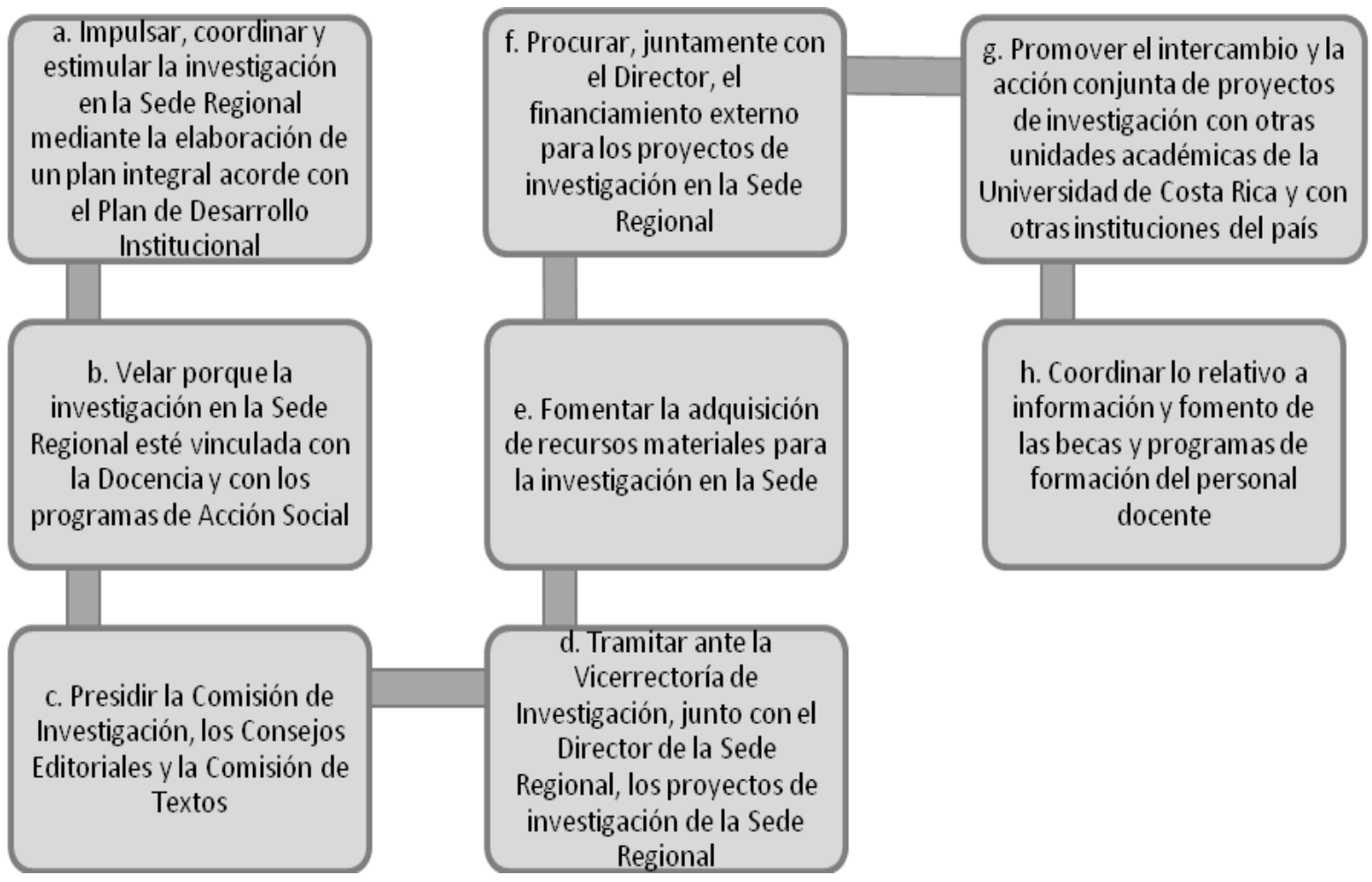

Fuente: Elaboración propia a partir de Universidad de Costa Rica (1998, p. 4). 
De manera paralela al desarrollo de la actividad investigativa en esta Sede Universitaria, se funda la Revista InterSedes, en el año 2000, como una revista de la Universidad de Costa Rica especializada en estudios regionales de las zonas de influencia de estas unidades académicas, con el propósito de difundir el conocimiento científico y cultural que se produce en las sedes regionales. Este hecho revistió gran importancia como factor de motivación hacia la producción intelectual dentro de la comunidad académica, y promovió la publicación de resultados de las investigaciones realizadas. La Revista Inter Sedes se publica 3 veces al año y recibe colaboraciones de la comunidad nacional e internacional. A la fecha, se han publicado 26 números, las cuales a partir del N²0 corresponden al formato de Versión Electrónica.

Es menester mencionar que el volumen 2, Números 2-3 (2001), de la respectiva Revista fue dedicado a la Licda. Mireya Hernández Faerron, profesora Emérita de la UCR y Exdirectora de la Sede de Guanacaste, quien enfatiza que la falta de medios de comunicación es una gran limitante en las regiones y un obstáculo para su desarrollo. Asimismo, señala:

Creo que esta Revista será un vehículo de integración universitaria, que aportará conocimiento necesario de las regiones hacia la Sede Central y de ésta a aquellas, en la búsqueda de una educación superior más equitativa y pertinente para la formación de profesionales, mujeres y hombres, que contribuyan con acierto en la solución problemas de diversa índole que tiene el país, especialmente en su periferia. (Hernández, 2001, p.11)

En dicha Revista se publican dos artículos de académicos de la Sede de Guanacaste. El primero denominado Tendencias de Graduación en la Sede de Guanacaste de la Universidad de Costa Rica de Espinoza y Rosales (2001), que da a conocer datos de graduación desde 1976 hasta 1999, en términos de número de graduaciones por año, total de graduados, graduaciones por carrera, programas especiales y grados académicos otorgados; con ello, se quiere dar a conocer el aporte al desarrollo de la zona la formación de profesionales y técnicos en diversas áreas del saber. El segundo se titula Los desafíos de la Educación en Costa Rica de Díaz y Rosales (2001) trata el papel que ha desempeñado la educación en la contribución del desarrollo del país, así como los retos que deberá asumir en el siglo XXI, para continuar como gestora y moldeadora del desarrollo. 
También, se publican los poemas del profesor de la Sede, Juan Santiago Quirós denominado Hijo de sombras y Retrato de un hijo de sombras, así como los Trabajos Finales de Graduación que se presentaron en el 2000 en las carrera de Trabajo Social (5), Educación (1) y Agronomía (1) en torno a aspectos de zona. En ese mismo año en la citada revista se publican los proyectos vigentes debidamente inscritos ante la Vicerrectoría de Investigación, donde se enfatiza el predominio del área agronómica y turística, respectivamente, tal y como se muestra seguidamente en la figura 8.

Figura 8. Sede de Guanacaste. Proyectos de investigación vigentes en el 2001

\begin{tabular}{|c|l|l|}
\hline Total de proyectos & Áreas & Títulos de los proyectos de investigados \\
\hline $\mathbf{5}$ & Agronomía & $\begin{array}{l}\text { Rescate de especies vegetales } \\
\text { Adaptación de plantas medicinales } \\
\text { Adaptación de frutales } \\
\text { Nuevas tecnologías para palmito } \\
\text { Adaptación de especies nativas }\end{array}$ \\
\hline $\mathbf{3}$ & $\begin{array}{l}\text { Creación de microempresas turísticas } \\
\text { Desarrollo sostenible } \\
\text { Evaluación de recursos naturales en especies nativas }\end{array}$ \\
\hline
\end{tabular}

Fuente: Elaboración propia a partir de Revista InterSedes, Volumen 2, №2-3 (2001).

Estos proyectos de investigación buscan producir conocimiento en torno a las actividades productivas de gran importancia para la zona, dada la vocación agropecuaria y turística de la región.

Para el año 2004, se encuentran 15 proyectos de investigación debidamente inscritos ante la Vicerrectoría de Investigación, de los cuales 7 de ellos se orientan al desarrollo agropecuario, 1 a la problemática social, 2 al área tecnológica y el resto a diversas temáticas, entre ellas la educación y la matemática (Universidad de Costa Rica, 2004).

A continuación, en el gráfico 2 , se muestra porcentualmente el estado de la investigación por áreas en la década de 1994-2004, se advierte siempre la preeminencia del área agropecuaria sobre las demás, casi con un $50 \%$ de la totalidad de proyectos desarrollados en ese periodo. La sumatoria de las áreas agropecuaria, Turismo y Desarrollo Regional evidencian el interés por tratar temáticas que vinculen a la Sede con factores que afectan la zona de influencia. 
Gráfico 2. Sede de Guanacaste, Proyectos de Investigación 1994-2004

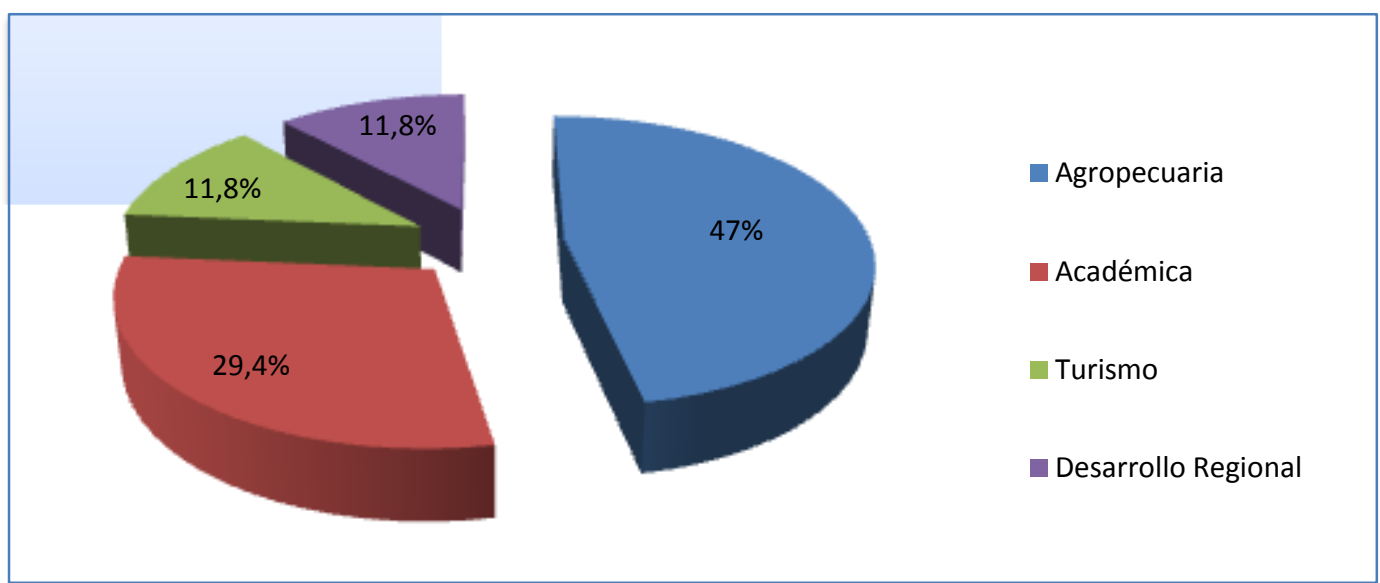

Fuente: Elaboración propia.

En el 2005, se reportan 9 proyectos, de los cuales 3 se enfocan a las áreas forestales y agrícolas; 1 específico de matemática; 4 del área de educación, con temáticas concretas de la Sede, como de la educación en general; 1 referido al campo bibliotecario y cultural, respectivamente. Para este año se nota una mayor presencia de temas relacionados con la situación educativa de la provincia (Universidad de Costa Rica, 2005).

Como parte de la difusión del conocimiento y expresión del desarrollo de la Sede, para el 2006 se puede apreciar una mayor diversificación de la temática que abordan los académicos en los artículos publicados, los cuales están vinculados con las carreras de Turismo Ecológico, Educación e Informática Empresarial y los Estudios Generales, así como a aspectos culturales de la zona. A continuación, la figura 9 da a conocer los artículos mencionados: 


\section{Figura 9. Artículos publicados Revista InterSedes $\mathbf{N}^{\circ} 13$}

\begin{tabular}{|c|c|}
\hline Área & Título de los artículos \\
\hline Turismo & $\begin{array}{l}\text { La Carrera de Turismo Ecológico de la Sede Guanacaste y el Desarrollo del } \\
\text { Ecoturismo en la Universidad de Costa Rica }\end{array}$ \\
\hline Turismo & $\begin{array}{l}\text { Percepción sobre el impacto de la actividad turística en una comunidad costera de } \\
\underline{\text { Guanacaste }}\end{array}$ \\
\hline Turismo & $\begin{array}{l}\text { La percepción del desarrollo eco turístico en dos comunidades del distrito Lepanto, } \\
\text { Puntarenas }\end{array}$ \\
\hline Turismo & $\begin{array}{l}\text { Planificación turística en zonas costeras de Costa Rica. Algunas referencias a } \\
\text { Playa Tamarindo (Santa Cruz, Guanacaste) }\end{array}$ \\
\hline Educación & $\begin{array}{l}\text { Consideraciones teóricas sobre el desarrollo de la inteligencia moral en niños } y \\
\underline{\text { niñas }}\end{array}$ \\
\hline Educación & $\begin{array}{l}\text { La especialización del y la docente de educación primaria en la Sede de } \\
\text { Guanacaste de la Universidad de Costa Rica }\end{array}$ \\
\hline Educación & $\begin{array}{l}\text { Formación de administradores(as) de la educación en el nivel de grado y } \\
\text { postgrado en la Sede de Guanacaste de la Universidad de Costa Rica }\end{array}$ \\
\hline Educación & $\begin{array}{l}\text { Diagnóstico sobre la forma de cómo los estudiantes del curso IF-2000 } \\
\text { Programación I, aprenden a obtener sus conocimientos }\end{array}$ \\
\hline Rescate popular & $\begin{array}{l}\text { Don Marcos Duarte Álvarez, uno de los últimos marimberos y marimbistas del siglo } \\
\underline{X X}\end{array}$ \\
\hline Rescate Popular & La Ciudad Blanca: Apuntes para una historia de Liberia \\
\hline Rescate Popular & Producción artística \\
\hline Rescate Popular & Documentos para la historia de Guanacaste \\
\hline Rescate Popular & $\begin{array}{l}\text { Reseñas Víctor Manuel Alvarado. La caída del último higuerón. San José: Editorial } \\
\text { Lunes, } 2007\end{array}$ \\
\hline
\end{tabular}

Fuente: Elaboración propia a partir de Revista InterSedes Volumen VII, №13 (2006).

Para este mismo período, la tendencia agropecuaria que caracterizaba los tópicos de proyectos de años anteriores va disminuyendo para dar paso al sector social y ambiental, debido al cambio del uso del territorio agrícola y gestión de nueva modalidad privada, para dar paso a un modelo socioeconómico de desarrollo basado en la actividad turística, crecimiento del sector hotelero y de servicios. Esta inclinación temática refleja que la prioridad ya no es el campo agrícola y ganadero, tal y como se visualizaba en informes anteriores, sobre todo, en los primeros años, sino continuar labores tendientes a analizar la problemática social, 
educativa y cultural dada la importancia que ha ido asumiendo en la región el tema de la guanacastequidad.

En los años 90, el período de transición del sector económico iniciado, consolida la estructura de servicios, con predominio del turismo masivo y desarrollo de bienes raíces como negocios de corporaciones de inversionistas nacionales y extranjeros, como las operadoras hoteleras internacionales. Esto tiene gran impacto en la población de menos recursos en lo económico y social. (Hernández, 2013, p. 263)

En el Informe de Investigación correspondiente al periodo 2006, se registran 12 proyectos inscritos ante la Vicerrectoría de Investigación. Según este informe, los tópicos están vinculados con áreas sociales, ambientales, turísticas, culturales, agrícolas y otros, a tono con la dinámica de desarrollo de la región, pero se nota una preeminencia.

De igual manera, el Informe del 2008 da cuenta que entre 1998 y el 2010 se desarrollaron en la Sede de Guanacaste 32 proyectos, 9 corresponden a Agronomía y 10 a Ciencias Sociales, incluida el área de Educación, áreas que reflejan los datos más altos. Los restantes se ubican en otros campos como Turismo, Patrimonio Cultural, entre otros.

Para el 2011, se inscribieron 5 nuevos proyectos de los Departamentos de Ciencia y Tecnología y del Departamento de Filosofía, Artes y Letras. Además, hay 2 proyectos de Inter Sedes, 2 proyectos de vinculación externa y 1 actividad de investigación: Expo UCR- Liberia. Finalmente, para el 2012 se registran diversos proyectos de investigación que trabajan temáticas variadas, tales como lo educativo, lo agropecuario, lo turístico y la historia regional (figura 10). 


\section{Figura 10. Proyectos de investigación 2012}

\begin{tabular}{|c|c|}
\hline Área & Proyectos de investigación \\
\hline Agronomía & $\begin{array}{l}\text { Dinámica de poblaciones de aves, mamíferos y macrohongos del bosque Ramón Álvarez, } \\
\text { Recinto de Santa Cruz }\end{array}$ \\
\hline Agronomía & $\begin{array}{l}\text { Venta de productos agrícolas de resultados de experimentos y alquileres de cabinas de la finca } \\
\text { Santa Cruz }\end{array}$ \\
\hline Agronomía & Evaluación de mezclas de sustratos orgánicos para la producción de almácigos en Guanacaste \\
\hline Agronomía & $\begin{array}{l}\text { Rehabilitación, desarrollo y propagación de especies del banco de germoplasma en bambú y } \\
\text { adaptación de un jardín de pastos en la Finca Experimental de Santa Cruz }\end{array}$ \\
\hline Agronomía & $\begin{array}{l}\text { Rehabilitación, mantenimiento y desarrollo de bancos de germoplasmas frutales en la Finca } \\
\text { Experimental de Santa Cruz }\end{array}$ \\
\hline Educación & $\begin{array}{l}\text { Evaluación del Impacto del programa curricular del nivel interactivo II en la Dirección Regional } \\
\text { Liberia }\end{array}$ \\
\hline Educación & $\begin{array}{l}\text { Fortalezas y debilidades en la formación de estudiantes bilingües en I y II Ciclo de Educación en } \\
\text { Guanacaste }\end{array}$ \\
\hline Educación & $\begin{array}{l}\text { Diagnóstico y evaluación de necesidades en el aprendizaje del idioma inglés en estudiantes de } \\
\text { Turismo Ecológico de la Universidad de Costa Rica }\end{array}$ \\
\hline Historia & $\begin{array}{l}\text { Historia Regional de Guanacaste, análisis y seguimiento de una región histórica de Costa Rica, } \\
\text { siglo XVII, XVIII, XIX }\end{array}$ \\
\hline Turismo & $\begin{array}{l}\text { Ecología del color de los huevos de aves limícolas (charadri) en ambientes tropicales y } \\
\text { mediterráneos }\end{array}$ \\
\hline Académica & cesidades de la Investigación educativa en la Región Chorotega \\
\hline
\end{tabular}

Fuente: Elaboración propia a partir de Universidad de Costa Rica (2012).

El Gráfico 3 integra, a modo de resumen, la cantidad de proyectos de la Sede en el período 2004 al 2012, donde se evidencia claramente la diversidad de áreas trabajadas; el área agropecuaria sigue teniendo un predominio mayor, seguido del área académica y de educación.

Gráfico 3. Sede de Guanacaste. Proyectos de Investigación 2004-2012

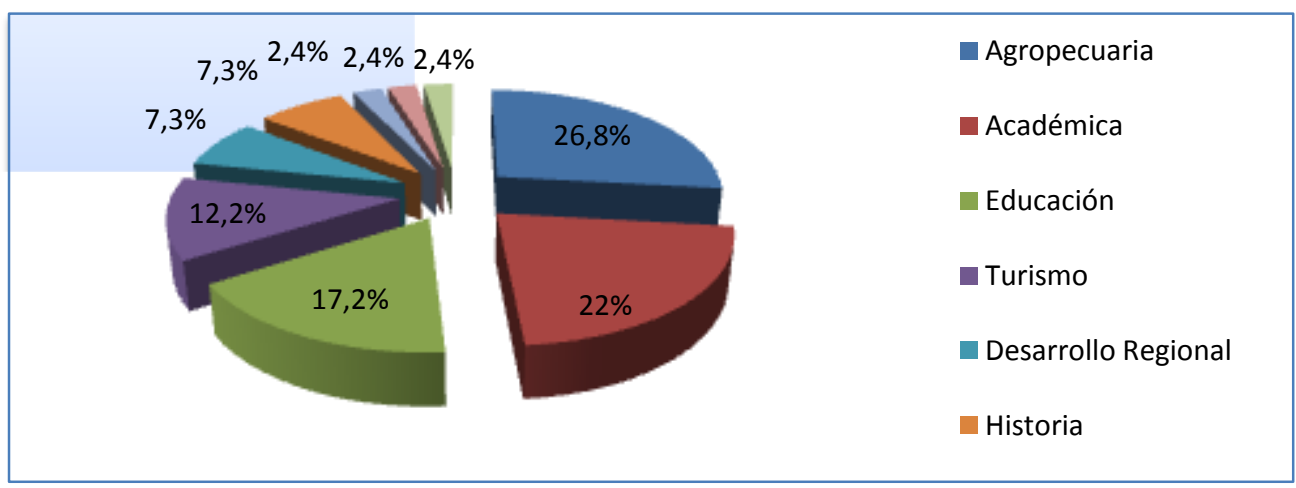

Fuente: Elaboración propia a partir Universidad de Costa Rica (2012). 
En la Figura 11 se presenta, a manera de resumen, una síntesis por áreas y por década, a partir de 1983, cuando empieza a tomar impulso la investigación en la Sede Guanacaste.

Figura 11. Trayectoria de la investigación por áreas y décadas
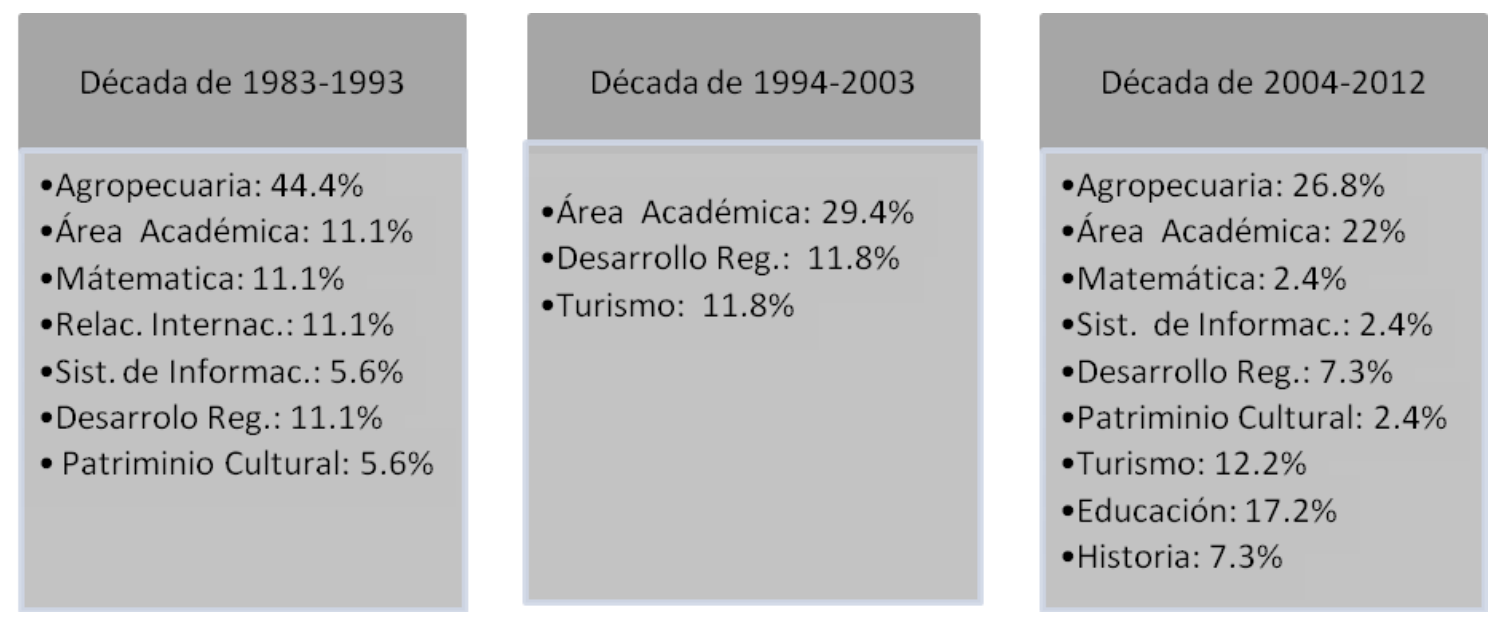

Fuente: Elaboración propia a partir de Universidad de Costa Rica (1993, 2004, 2005, 2006, 2008 y 2012).

Para dar paso al cierre de este apartado, se muestra una comparación de la trayectoria de la investigación por décadas, en la que se destaca que la última presenta casi tres veces más presencia de proyectos de investigación con respecto a las dos décadas anteriores (figura 12), dada la experiencia acumulada, la consolidación de un cuerpo docente y personal de apoyo, mejoramiento de la infraestructura y soporte tecnológico y bibliotecario, vinculación con zona de influencia, definición de políticas y de apoyo a la investigación, así como la creación de mecanismos de difusión y divulgación.

Figura 12. Comparación de cantidad de Proyectos de Investigación, 1983 -2012

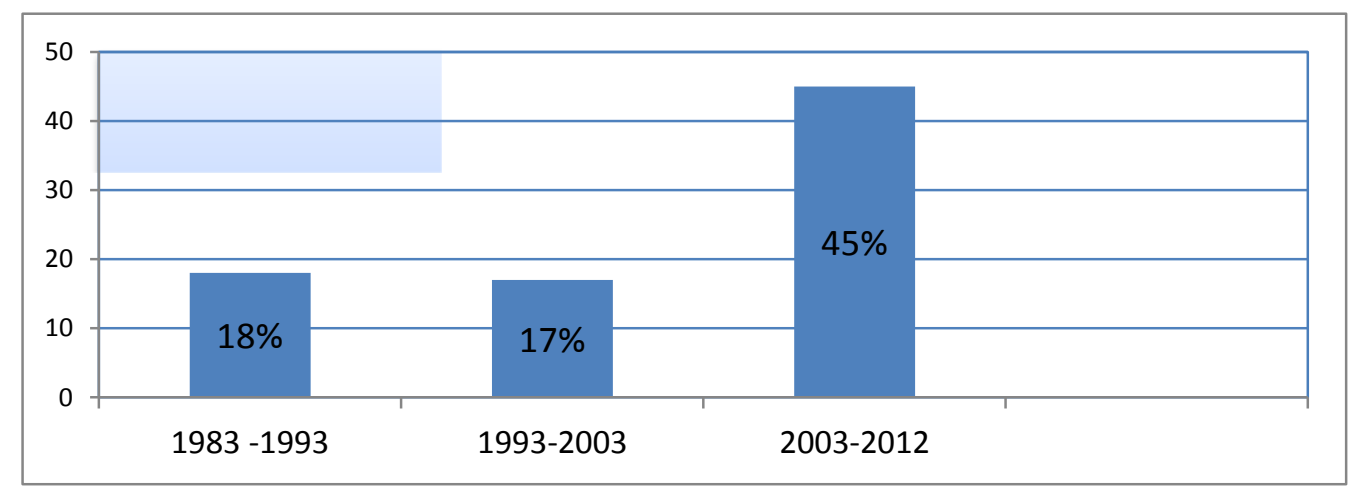

Fuente: Elaboración propia. 
Como se puede observar, la trayectoria de investigación en la Sede Guanacaste ha dado importantes productos; sin embargo, aún no ha sido una tarea trascendental para el quehacer académico en esta Sede, de ahí que su influencia directa en el quehacer universitario y a nivel regional parece muy limitada, por lo que se exhorta a la comunidad universitaria y autoridades a:

analizar, diagnosticar y resolver la situación de aquellas unidades académicas en las que la investigación se encuentre en un punto de desarrollo preliminar. Este tipo de análisis debe pasar por la consolidación de plazas académicas en dichas unidades, y continuar con un plan de fortalecimiento del recurso humano con posgrado en las mismas. Además, se deben diseñar estrategias de desarrollo de la investigación, mediante actividades como la traída de expertas y expertos que actúen como elementos promotores y aglutinadores, como formadores de cuadros; asimismo, se debe favorecer la capacitación de los académicos alrededor de otros grupos de la UCR que tengan un grado mayor de desarrollo; la utilización de grupos consolidados como escuelas de cuadros académicos para grupos con menor grado de desarrollo es una posibilidad muy interesante que debe valorarse y promoverse. Finalmente, las políticas de contratación de docentes deben enmarcarse en esta perspectiva. (Gutiérrez, 2005, p. 3)

Es decir, se hace necesario analizar las condiciones en las cuales se desenvuelve la investigación, los factores que inciden en esta, la manera en que los incentivos y desincentivos la impactan, la necesidad de realizar esfuerzos sustanciales para construir capacidades sostenibles de investigación, entre otros aspectos. Así,

La investigación y la docencia deben conformar una unidad de acción para el investigador, ya que es ésta la mejor manera de aportar al estudiante contenidos que eleven el nivel académico; esta unidad permite al profesor reflexionar sobre sus inquietudes intelectuales y científicas en la medida en que investiga y traspasa parte de esas inquietudes y conocimientos a un auditorio preparado; de esta manera logra acercar al estudiante realmente a la realidad nacional, con conocimientos extraídos de esa realidad y superando el nivel mediocre y pragmatista. (Vélez y Dávila, 1984, p. 49)

Además, se requiere de un esfuerzo importante de replanteo de las políticas y prioridades de investigación en la Sede Guanacaste, tarea pendiente y necesaria que, de 
realizarse, conducirá a propiciar espacios y condiciones favorables al desarrollo de la investigación, pues

La realidad guanacasteca hoy es muy compleja: contamos con un aeropuerto internacional que ha puesto a Liberia en el mapa del mundo y hay predominio de lo urbano sobre lo rural; las empresas agroexportadoras (meloneras, mango, piña), la agroindustria cañera con sus grandes ingenios (azúcar, alcohol), disponer de moderna tecnología de punta; los atractivos que ofrecen grandes empresas turísticas como Península de Papagayo, con la cual tenemos excelentes y positivas relaciones, el tener de vecino a un ex astronauta de reciente ingreso en el salón de la fama del museo de la NASA, Dr. Franklin Chang Díaz y su visionaria empresa Ad Astra Rocket, así como nuestra colega internacional, la Earth, entre otros importantes rasgos, como la escasez de nuestros recursos naturales: los bosques, el agua, los problemas sociales, entre otros, debe estimularnos como universitarios a honda reflexión (Hernández, 2013, p.162).

\section{Conclusiones}

La celebración del 40 aniversario de la Sede Guanacaste es momento vital para reflexionar acerca de la situación de la actividad investigativa en esta Unidad Académica, su vínculo con la docencia y la acción social, respectivamente, de tal manera que esta reflexión pueda servir para posicionar el compromiso institucional con la investigación, consolidar lo que se tiene, identificar, superar obstáculos y fortalecer aquellas áreas que aún están en vías de desarrollo o sin desarrollar en su totalidad.

Por cuanto, la reconstrucción de la trayectoria de la investigación en este recinto deja entrever que tal función universitaria aún no ha logrado consolidarse, a pesar de los esfuerzos realizados por los académicos en este sentido, a lo largo de estos 40 años de vida institucional; sin embargo, dadas las áreas en las que se ha investigado, la experiencia acumulada, infraestructura y personal interesado es posible afirmar que las investigaciones que se han llevado a cabo tienen pertinencia, al contribuir al desarrollo regional. Esto se evidencia en la información extraída de los documentos consultados y expuestos en el desarrollo de este artículo.

No obstante estos logros, existe una crítica constante en los documentos estudiados en torno a la falta de financiamiento y de asignación de jornada laboral para la investigación, 
insuficiencia de recursos logísticos y de incentivos a corto plazo para los investigadores, de tal manera que propicien el desarrollo adecuado de los proyectos de investigación planteados a lo largo de la historia de la Sede. Por su lado, la forma de distribución de la jornada docente se ha quedado atrapada en una auténtica trasmisión del conocimiento, centrado en la docencia, sin trascender hacia la producción y generación de nuevos conocimientos y tecnología, que permita resignificar los problemas y las necesidades del desarrollo. Es decir, que la actividad investigativa se posicione en el quehacer de la Sede como un componente indispensable de la actividad docente, ya que en la práctica la acción docente requiere de la investigación para revitalizarse continuamente.

De igual manera, en materia de investigación se percibe que la descentralización aún no es efectiva, por lo que se sigue dependiendo de la tramitología ante las instancias respectivas.

A pesar de existir condiciones poco favorables para la implementación del quehacer investigativo, se perciben evidencias significativas de resultados en esta área, por parte de la comunidad académica, quienes han asumido la responsabilidad de contribuir al progreso de la región tendiente a vislumbrar alternativas de desarrollo, con participación de otras instituciones o entidades existentes en la zona de influencia de la Sede, así como continuar con la promoción de la identidad guanacasteca y su cultura, iniciada desde su creación, a través del desarrollo diversas investigaciones y publicaciones sobre costumbres, tradiciones, lengua, literatura y folclor.

Es menester desatacar que en la década de los 80, en Guanacaste predominaba una economía agrícola, fundamentada en productos con una vinculación relativamente fuerte con el resto de la economía nacional, aunque con algunos vínculos al mercado externo. La principal actividad productiva era la ganadería, con una emergente producción agroindustrial de caña de azúcar y granos básicos como el arroz, maíz y frijoles, destinados al consumo interno, así como la introducción de otros productos no tradicionales como el melón y los cítricos. A partir de la crisis que se da en el agro y producto de la política reformista, Guanacaste pasa entre 1984 y el 2000 de ser una región eminentemente agrícola para convertirse en una de servicios, ligada al peso del turismo como actividad predominante en las zonas costeras y otras zonas (Carrillo, Santa Cruz y Liberia), donde Guanacaste es promocionado como un destino ecológico que ofrece un escenario que combina un turismo 
ecológico que permite acceso a diversas áreas protegidas, caracterizadas por una gran biodiversidad y accesibilidad, a la par de un turismo de sol y playa.

La especialización de Guanacaste como polo de desarrollo turístico ha implicado cambios cuantitativos como cualitativos, incidiendo en lo social, laboral, ambiental y cultual, el paso de un turismo de tránsito y de negocios a uno de ocio y consumo, con mayores rentas, flujos de turistas, inversión turística y construcción de infraestructura hotelera con mayor infraestructura como canchas de golf y marinas. Esto ha dado cabida a una transición del turismo basado en cabinas operadas familiarmente para dar espacio al predominio de los mega proyectos hoteleros, que al parecer constituyen la apuesta política para la eliminación de las problemáticas ligadas con el empleo y la desigualdad en la región.

Esta dinámica de desarrollo que ha experimentado Guanacaste amerita la realización de investigaciones que den cuenta del impacto que provocan estas transformaciones en lo social, cultural, ambiental.

Es decir, se evidencia la firme convicción de realizar la Investigación como una responsabilidad social, de ahí que sea hace necesario elaborar un estado del arte de la situación de la investigación universitaria y de los mecanismos de incentivos, con miras a fortalecer capacidades institucionales de investigación universitaria, a partir de:

- Identificar las políticas nacionales de Ciencia, Tecnología e Innovación en relación con las universidades, en particular con la UCR y la Sede.

- Identificar fuentes públicas y privadas de financiamiento de la investigación a nivel regional, así como establecimiento de alianzas estratégicas con los gestores del desarrollo regional.

- Determinar el nivel de cooperación y de colaboración entre el sector privado y la Sede Guanacaste en materia de generación de conocimiento, transferencia de conocimiento y tecnología.

- Elaboración del estado del arte con respecto a difusión e información de los resultados de la investigación en la Sede Guanacaste.

- Valorar la pertinencia y calidad de la investigación de la Sede, para vislumbrar caminos pertinentes para la actividad investigativa.

- Definir el perfil académico de los docentes investigadores. 


\section{Referencias}

Alfaro, Lidia y otras. (1981). Bases teórico metodológicas del Taller en Costa Rica y resultados de su aplicación: un estudio comparativo. (Seminario de Graduación para optar al grado de Licenciatura en Trabajo Social). Universidad de Costa Rica, San José, Costa Rica.

Caamaño, Carlos. (1972). Centros Universitarios Regionales. San José, Costa Rica: Departamento de Publicaciones de la Universidad de Costa Rica.

Camacho, Daniel. (1997). Saludo. Revista de Ciencias Sociales de la Universidad de Costa Rica, (75), 5.

Castro, Silvia. (2009). Costa Rica frente a la regionalización de la educación superior. El primer centro universitario regional en San Ramón, Alajuela. Revista Inter Sedes, $X(18)$, 174-204.

Cavallini, Ligia. (1974). La Municipalidad de Nicoya 1820-1824. Revista de la Universidad de Costa Rica, (38), 73-79.

Díaz, Flora y Rosales, Rosa. (2001). Los desafíos de la Educación en Costa Rica. Revista InterSedes, 2(2-3), 110-134.

Durán, Fernando. (agosto, 1979). Filosofía de la descentralización en los Centros Regionales. Ponencia presentada en el Primer Congreso del Centro Universitario de Guanacaste, Liberia, Costa Rica.

Espinoza, Albert y Rosales, Rosa. (2001). Tendencias de graduación en la Sede de Guanacaste de la Universidad de Costa Rica. Revista InterSedes, 2(2-3), 123-134.

Fonseca, Virginia. (agosto, 1979). Inserción del Centro Universitario de Guanacaste en la Universidad de Costa Rica. Ponencia presentada en el Primer Congreso del Centro Universitario de Guanacaste, Liberia, Costa Rica.

García, Guillermo y Chaves, Sergio. (1974). El Coyol, vino guanacasteco. Revista de la Universidad de Costa Rica, (38), 25-37.

García, Guillermo. (1977). Mario Cañas Ruiz. Un artista Guanacasteco. San José Costa Rica.

Gutiérrez, José María. (setiembre, 2005). Guía para la investigación científico-tecnológica en la Universidad de Costa Rica: situación actual y perspectivas. Ponencia presentada en el Foro de reflexión sobre Calidad y pertinencia de la investigación científica en la Universidad de Costa Rica, San José, Costa Rica.

Hernández, Mireya, Dávila, Carlos y Jaén, Julio César. (1977). Monografía del Cantón Carrillo 1877-1977. San José, Costa Rica: Editorial Universidad de Costa Rica.

Hernández, Mireya. (1974). Reseña Crítica de algunos libros y estudios sobre Guanacaste. Revista de la Universidad de Costa Rica, (38), 127-162.

Hernández, Mireya. (2001). Presentación. Revista Inter Sedes, 2(2-3), 11. 
Hernández, Mireya. (2013). Semblanza histórica de la Sede Universitaria de Guanacaste. Revista InterSedes, XIV(29), 152-163. Universidad de Costa Rica.

Láscaris, Constantino. (1974). El Guanacaste. Revista de la Universidad de Costa Rica, (38), 21-24.

Loría, Ana Ligia. (1997). Semblanza histórica de la Sede de Guanacaste. Revista de Ciencias Sociales de la Universidad de Costa Rica, (75), 113-119.

Margery, Enrique. (1976). Algunas reflexiones en torno al quehacer de la investigación en los Centros Universitarios de la Universidad de Costa Rica. San José, Costa Rica: Centro Universitario de Occidente.

Murillo, Manuel. (agosto, 1979). La Investigación en Guanacaste. Ponencia presentada en el Primer Congreso del Centro Universitario de Guanacaste, Liberia, Costa Rica.

Rivas, Marlon. (octubre, 2011). Docencia, investigación y vinculación social. En Didáctica de la lengua I. Universidad Experimental Rafael María Baralt (UNERMB). Recuperado http://didacticadelalenguauno.blogspot.com/2011/10/docencia-investigacion-yvinculacion.html.

Rosales, Rosa. (1996). Contribución de la Acción Social al desarrollo regional. Revista de Ciencias Sociales de la Universidad de Costa Rica, 2(75), 121-133.

Universidad de Costa Rica, Consejo Universitario. (setiembre, 1998). Reglamento de la Sede Regional de Guanacaste. San José, Costa Rica: Gaceta Universitaria 26-98, 24-09-98.

Universidad de Costa Rica, Sede de Guanacaste. (1993). Informe de la Coordinación de Investigación. Liberia, Costa Rica: Coordinación de Investigación.

Universidad de Costa Rica, Sede de Guanacaste. (2004). Informe de la Coordinación de Investigación. Liberia, Costa Rica: Coordinación de Investigación.

Universidad de Costa Rica, Sede de Guanacaste. (2005). Informe de la Coordinación de Investigación. Liberia, Costa Rica: Coordinación de Investigación.

Universidad de Costa Rica, Sede de Guanacaste. (2006). Informe de Labores. Liberia, Costa Rica: Coordinación de Investigación.

Universidad de Costa Rica, Sede de Guanacaste. (2008). Informe de Labores. Liberia, Costa Rica: Coordinación de Investigación.

Universidad de Costa Rica, Sede de Guanacaste. (2012). Informe de Labores. Liberia, Costa Rica: Coordinación de Investigación.

Universidad de Costa Rica. (1990). Estatuto Orgánico. San José, Costa Rica: Departamento de Publicaciones.

Vélez, Ignacio y Dávila, Ricardo. (1984). De la investigación universitaria en Colombia. Revista Superior y Desarrollo, 3(1), 48-54. 